\title{
Correction to: A review on the genus Populus: a potential source of biologically active compounds
}

\author{
Ishita Guleria - Amita Kumari (1) Marie-Aleth Lacaille-Dubois • \\ Nishant • Vikas Kumar - Adesh K. Saini · Jyoti Dhatwalia - Sohan Lal
}

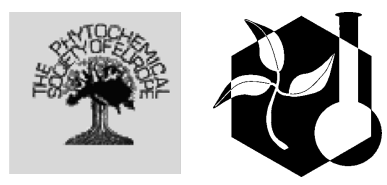

Published online: 23 October 2021

(C) Springer Nature B.V. 2021

\section{Correction to: Phytochem Rev \\ https://doi.org/10.1007/s11101-021-09772-2}

In the original publication, the affiliation for one of the co-authors (Adesh K. Saini) was published incor-

The original article can be found online at https:// doi.org/10.1007/s11101-021-09772-2.

I. Guleria · A. Kumari $(\bowtie) \cdot$ J. Dhatwalia $\cdot$ S. Lal

School of Biological and Environmental Sciences, Faculty

of Sciences, Shoolini University, Solan,

Himachal Pradesh 173212, India

e-mail: amitabot@gmail.com

\section{M.-A. Lacaille-Dubois $(\square)$}

Department of Pharmacognosy, EA 4267, UFR of Health Sciences, University of Bourgogne Franche-Comté, 21079 Dijon Cedex, France

e-mail: Marie-Aleth.Lacaille-Dubois@u-bourgogne.fr

\section{Nishant}

Department of Chemistry, St. Beads College, Shimla,

Himachal Pradesh, India

\section{Kumar}

Faculty of Biotechnology and Applied Sciences, Shoolini University, Solan, Himachal Pradesh 173212, India rectly. The correct affiliation is given in this correction.

The original article has been corrected.

Publisher's Note Springer Nature remains neutral with regard to jurisdictional claims in published maps and institutional affiliations.

\author{
A. K. Saini \\ Department of Biotechnology MMEC, Central Research \\ Laboratory MMIMSR, Maharishi Markandeshwar \\ (Deemed to be University), Mullana, \\ Haryana, India
}

